Bull. Mater. Sci., Vol. 35, No. 4, August 2012, pp. 539-544. (C) Indian Academy of Sciences.

\title{
Improvement in tensile properties of PVC-montmorillonite nanocomposites through controlled uniaxial stretching
}

\author{
ADNAN SARFRAZ, MUHAMMAD FAROOQ WARSI, MUHAMMAD ILYAS SARWAR and \\ MUHAMMAD ISHAQ* \\ Department of Chemistry, Quaid-i-Azam University, Islamabad 45320, Pakistan
}

MS received 29 March 2011

\begin{abstract}
In this paper we present the results exhibiting an improvement in the tensile properties of polyvinyl chloride (PVC)-montmorillonite nanocomposites through uniaxial stretching. The clay was dispersed in PVC matrix with the help of dodecylamine. PVC-montmorillonite nanocomposites films containing varying amounts of clay (0-5\%) were produced through solution elution technique. The films were stretched uniaxially at a constant temperature of $80^{\circ} \mathrm{C}$ in three different steps using controlled loads. X-ray diffraction and stress-strain curves were obtained for both unstretched and stretched films in order to determine the improvement in various properties. The controlled uniaxial stretching of films close to the softening temperature of PVC has resulted in enhancement in the degree of crystallinity in the nanocomposites. This improvement in the structural order has also imparted increase in tensile strength and Young's modulus of the nanocomposite films.
\end{abstract}

Keywords. PVC; montmorillonite; nanocomposites; X-ray diffraction; tensile properties.

\section{Introduction}

There have been many examples of composite materials in which polyvinyl chloride (PVC) had been used as matrix. Recently, interest in nanocomposites of PVC incorporating clay sheets as reinforcement has also been reported (Choudhury and Misra 2010; Wang and Wilkie 2002; Wang et al 2002). The structural features and physical, thermal, and mechanical properties of PVC-montmorillonite materials are also currently of huge interest (Bibi et al 2007; Zulfiqar et al 2008; Pagacz and Pielichowski 2009). These materials are characterized as nanocomposites, since complete random dispersion of the montmorillonite layers is achieved and the layer thickness is in the order of $1 \mathrm{~nm}$.

PVC is a well known resin and can be molded in various rigid or plasticized forms. Its softening temperature is around $86^{\circ} \mathrm{C}$ and it shows thermal degradation above $150^{\circ} \mathrm{C}$. It is mostly amorphous due to largely atactic configuration but can exhibit up to $5 \%$ degree of crystallinity when drawn into fibres because of inherent preference of syndiotactic over the isotactic configuration (McKinney and Foltz 1967; Juijn et al 1973). Its hard form can withstand a tensile stress in the order of 46-52 MPa before yielding, while the soft form can elongate up to $60 \%$ before breaking (Cheremisinoff 1989). These and other properties make PVC a very suitable material to be used as matrix in a variety of composite materials (Benderly et al 2008). A variety of filler materials have been used and reported to have improved the longevity and

\footnotetext{
*Author for correspondence (mishaq@qau.edu.pk)
}

thermal degradation properties of PVC (Wang and Wilkie 2002).

Montmorillonite is a typical smectite clay consisting of regular stacks of negatively charged aluminosilicate layers separated by layers containing charge balancing cations. The structure within the layer is highly crystalline and individual layers are about $1 \mathrm{~nm}$ apart. Swelling occurs when water molecules enter into the layers accompanied by an increase in the interlayer distances. The use of montmorillonite is widespread due to its many applicable properties including large surface area of layers and ion exchange capacity (Figueras et al 1990; Ray and Okamoto 2003; Gacitua et al 2005; Hussain et al 2006).

Virgin montmorillonite is hydrophilic in nature which can be changed to organophilic by treating with intercalating agents such as dodecylamine. The positively charged ammonium head enters into layers replacing other cations and pushing layers apart to accommodate its long flexible organic tail. The organophilic clay can then be easily dispersed in PVC (Lepoittevin et al 2003). The properties of PVC-clay materials depend on average size of clay particle, degree of dispersion, nature of compatibilizing agent, conditions and method of preparation (Wang and Wilkie 2002; Wang et al 2002; Gong et al 2004). It has been reported that PVCclay materials show better thermal stability and improved mechanical properties. However, optimum improvement is achieved when clay content is kept below 5\% (Wan et al 2003).

In this paper we present the effect of clay contents on the crystallinity and tensile properties of the PVC-montmorillonite nanocomposite films. The films were 
stretched uniaxially in three steps under controlled loading at a temperature just below the glass temperature $\left(T_{\mathrm{g}}\right)$ of PVC, so that its segments can have limited freedom to move over each other and produce better alignment without breaking. The unstretched and stretched films were subjected to $\mathrm{X}$-ray diffraction and tensile measurements in order to study the structural features and mechanical properties and the corresponding changes that appeared due to stretching.

\section{Experimental}

\subsection{Intercalation of montmorillonite}

Montmorillonite clay was intercalated with dodecylamine by mixing a dispersion of $20 \mathrm{~g}$ of Na-montmorillonite (cation exchange capacity, $119 \mathrm{meq} / 100 \mathrm{~g}$ ) in $400 \mathrm{~mL}$ of water and a solution of $9 \mathrm{~g}$ of dodecylamine and $5 \mathrm{~mL}$ of concentrated hydrochloric acid in $100 \mathrm{~mL}$ of water. The mixture was stirred vigorously for $3 \mathrm{~h}$ at $60^{\circ} \mathrm{C}$. A white precipitate consisting of intercalated clay was separated, washed with hot water and dried until constant weight.

\subsection{Preparation of $P V C$-montmorillonite films}

PVC-montmorillonite films were prepared by mixing required quantities of pure PVC and intercalated clay using THF as solvent. The mixture was stirred for $24 \mathrm{~h}$ to ensure homogeneous dispersion of clay layers in PVC and then transferred into a petri dish. The petri dish was placed on a leveled surface and slow evaporation of the solvent produced a film of uniform thickness. In addition to the pure PVC film, different nanocomposite films containing $0.5,1 \cdot 0$, $1 \cdot 5,2 \cdot 0,2 \cdot 5,3 \cdot 0,4 \cdot 0$ and $5 \cdot 0 \mathrm{wt} \%$ clay were prepared. Three sets of such films were prepared in order to average out the behaviour of each composition. All films were of same thickness i.e. $0.5 \mathrm{~mm}$.

\subsection{Stretching of films}

A specimen with $5 \mathrm{~cm}$ length and $1 \mathrm{~cm}$ width was cut from each film and stretched using a custom-made apparatus shown schematically in figure 1 . It used a vernier caliper arm offering reading accuracy of $0.05 \mathrm{~mm}$, standing upright on a stable base. Usage of a commonly available vernier caliper for the construction gives the dual advantage of being easy to construct as well as resulting in accurate measurement. Metal clips were used to grip the strips firmly at both ends. A $3.5 \mathrm{~cm}$ long central portion of each strip was marked for stretching. The lower jaw with the required weight on it was kept fixed initially using a screw. The whole apparatus was placed in a pre-heated oven set at $80^{\circ} \mathrm{C}$. When the assembly attained the oven temperature, the screw at the lower jaw was loosened to let the specimen stretch freely under the applied load. The elongation of the marked portion was recorded as a function of time.

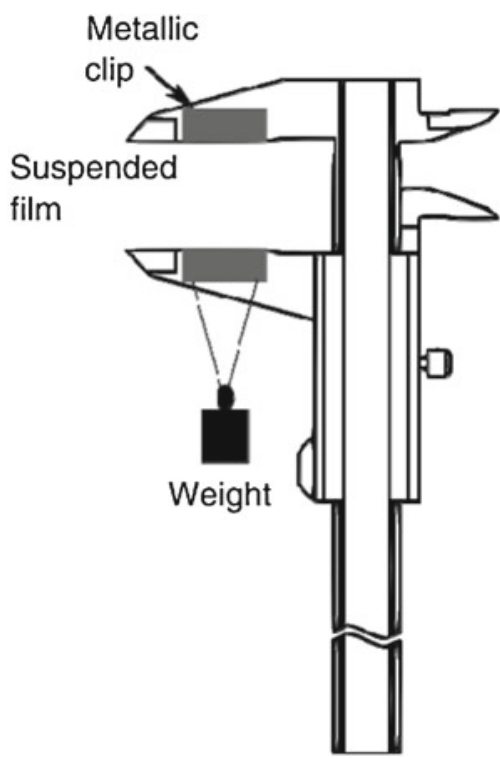

Figure 1. Schematic diagram for custom made apparatus for stretching of films.

The stretching of each specimen was carried out in three stages with different weights. In the first stage, the weight of lower movable part of assembly, which equals to $75 \mathrm{~g}$, was used to stretch the specimen. It was noted that the marked length ceased to increase after some time. Each sample was allowed to react to the applied load for $25 \mathrm{~min}$. After that, additional weight of $30 \mathrm{~g}$ was added to the pan and stretching was recorded for second stage for 25 more min. Again after reaching the same state, more weight of $20 \mathrm{~g}$ was added for the third stage for a duration of $25 \mathrm{~min}$. In this way, the maximum elongation was obtained in each case without breaking the specimen. Subjecting the films to a temperature above $85^{\circ} \mathrm{C}$, which is $T_{\mathrm{g}}$ of PVC resulted in continuous stretching until break.

\section{$2.4 X$-ray diffraction}

X-ray diffractometer Pak Diff 1000 was used to record diffraction patterns of the films and clay samples from 10 to $80^{\circ} 2 \theta$ at $25 \mathrm{~mA}$ and $40 \mathrm{kV}$ using $\mathrm{Cu}-\mathrm{K} \alpha$ radiation. $\mathrm{X}$-ray diffraction patterns of the virgin and intercalated clay and unstretched and stretched films containing $0,1,2,3$ and 4 wt $\%$ of clay, were obtained.

\subsection{Stress-strain analysis}

Stress-strain behaviour of unstretched and stretched films of pure PVC and of its nanocomposites, was studied in accordance with the method described under ASTM 882 standard (ASTM D882 - 10 2003). This test method covers the determination of tensile properties of plastics in the form of films having thickness of $<1 \mathrm{~mm}$. Tensile measurements were carried out using Testometric Universal Testing Machine 
M350/500, with a cross-head speed of $5 \mathrm{~mm} / \mathrm{min}$ and a load cell of $100 \mathrm{kgf}$ capacity with $1.0 \mathrm{mg}$ load detection capability. Four specimens of all the samples were tested and an average curve was obtained for each composition. The raw data in the form of engineering stress vs engineering strain were transformed into true stress vs true strain form for better presentation and comparison as per practice.

\section{Results and discussion}

Films of pure PVC and of PVC-montmorillonite nanocomposites containing $0.5,1.0,1.5,2.0,2.5,3.0,4.0$ and 5.0 $\mathrm{wt} \%$ of clay have been produced through solution elution technique. All the films were clear, smooth and transparent. Regions of films with uniform thickness were selected and cut for stretching and tensile testing purposes and other good portions were used in X-ray diffraction analysis.

\subsection{Stretching of films}

The length of each film is recorded as a function of time during each stretching stage and is presented in figure 2 . The total percent increase in length of each film after the three stages is given in table 1. Uniaxial stretching under a certain load at $80^{\circ} \mathrm{C}$ offers suitable physical conditions where segments of polymer chains experienced limited mobility along the stress direction resulting in certain increase in length of the films. Stretching with greater load as in the second and third stage produced more elongation.

Comparing the overall result of stretching of the films, it is obvious that as the clay content is increased, the percentage elongation decreased. The maximum increase of about $28 \%$ has been achieved in the films of pure PVC while the films with $5 \%$ clay contents have shown only $11 \%$

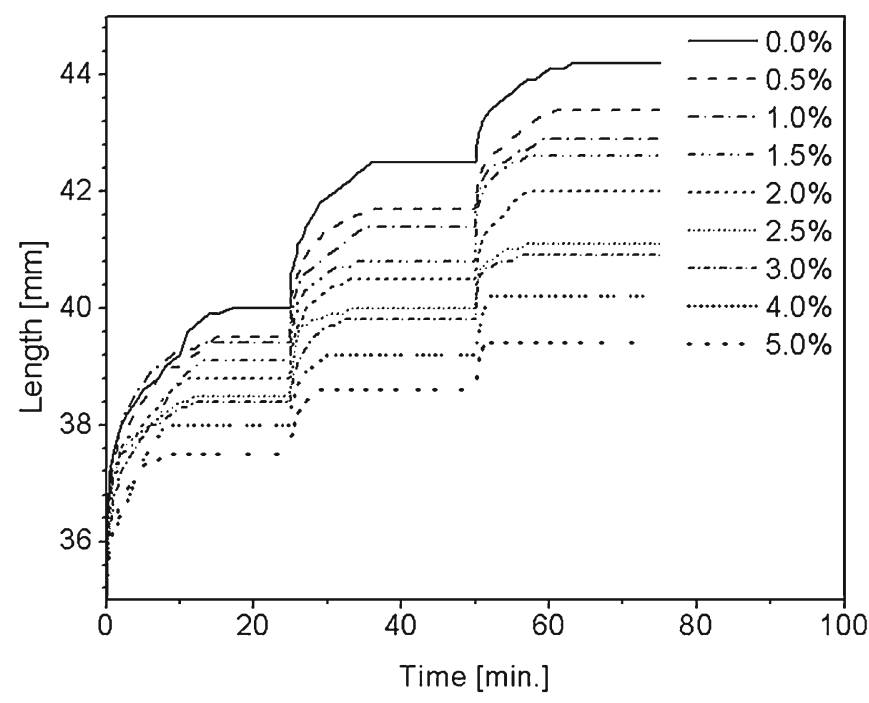

Figure 2. Sample length vs time during stretching of PVC films containing different amounts of montmorillonite. elongation. This can be explained by the fact that montmorillonite being an inorganic mineral with ordered structure in its layers resists the movement of polymer segments during the stretching process. Thus, the brittleness of films increases with increasing clay contents.

\subsection{X-ray diffraction of montmorillonite}

The diffractograms for non-intercalated and intercalated powder samples of montmorillonite are shown in figure 3 . The most prominent peak at $27.05^{\circ}$ present in the curve for virgin clay disappeared in that of the intercalated sample. Another relatively small peak at $55.50^{\circ}$ also vanished. These peaks correspond to the $d$-spacing of $3.29 \AA$ and $1.65 \AA$, respectively. As the value of ' $c$ ' parameter in unit cell of montmorillonite crystal structure is $9.92 \AA$ when $c$-axis is taken perpendicular to the layer plane, the above two peaks can be attributed as members of $00 l$ peaks. Their absence in the profile for intercalated clay sample indicates that the intercalation has been achieved as the clay layers had been separated apart as a result of insertion of positively charged

Table 1. Percent elongation of PVC-montmorillonite nanocomposite films.

\begin{tabular}{lc}
\hline Clay $(\mathrm{wt} \%)$ & Elongation $(\%)$ \\
\hline $0 \cdot 0$ & $27 \cdot 50$ \\
$0 \cdot 5$ & $25 \cdot 10$ \\
$1 \cdot 0$ & $22 \cdot 57$ \\
$1 \cdot 5$ & $20 \cdot 91$ \\
$2 \cdot 0$ & $19 \cdot 51$ \\
$2 \cdot 5$ & $17 \cdot 86$ \\
$3 \cdot 0$ & $16 \cdot 84$ \\
$4 \cdot 0$ & $13 \cdot 55$ \\
$5 \cdot 0$ & $11 \cdot 34$ \\
\hline
\end{tabular}

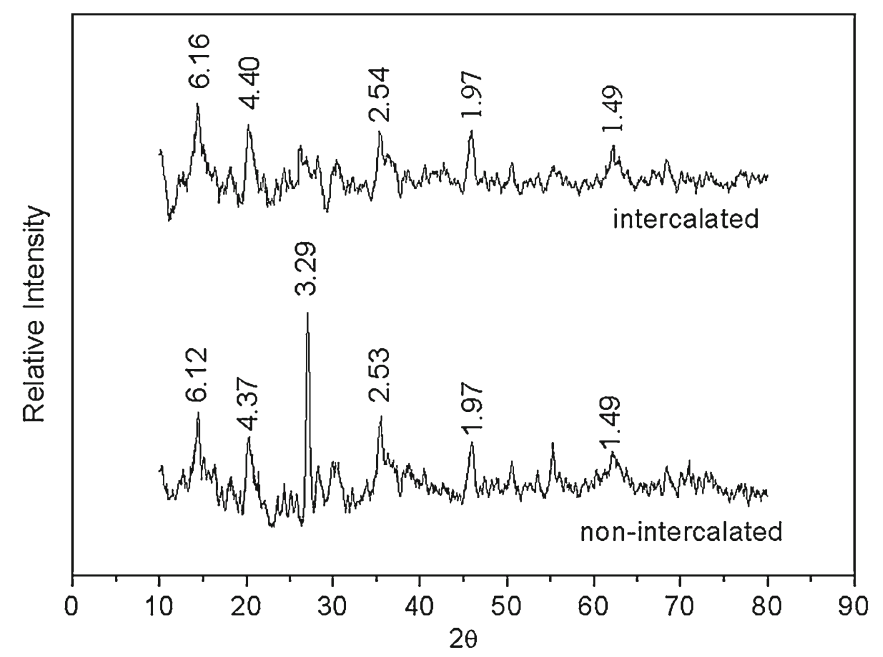

Figure 3. X-ray diffraction intensity profiles of non-intercalated and intercalated montmorillonite. 
dodecylamine molecules into the interlayer galleries. The other peaks which correspond to the $d$-spacing of planes formed by the atoms within each layer remained in tact and did not change upon intercalation.

\subsection{X-ray diffraction of nanocomposites films}

Figure 4 depicts the diffractograms of films of pure PVC and those of its nanocomposites containing 1, 2, 3 and $4 \mathrm{wt} \%$ of clay before and after stretching, respectively. All the profiles show the amorphous nature of PVC-montmorillonite nanocomposites. The intensity profiles of un-stretched films indicate the complete dispersion of clay in the PVC matrix. The small peaks budding out of the profiles of films with high clay contents belong to the set of clay peaks which remain unchanged upon intercalation. These peaks are more prominent in the profiles of films with higher clay contents. The intensity profiles of stretched films clearly indicate higher degree of structural order in these films. It can be observed that this stress-induced enhancement of structural order had been more pronounced in samples with higher clay contents.

\subsection{Mechanical properties}

The stress-strain data were recorded for three sets of unstretched and stretched films of all compositions. True stress vs true strain curves for one representative set of un-stretched films are presented in figure 5. Whereas, figure 6 shows similar curves for one representative set of stretched films. All the curves follow the behaviour of a typical viscoelastic polymer material, i.e. exhibiting initial linear rise, proportionality limit, yield point, neck formation, stress induced neck propagation and finally the break point. The values of various tensile parameters like Young's modulus, stress and strain at yield and break points, extracted from all these curves and averaged from the three specimens for each composition, are listed in table 2.
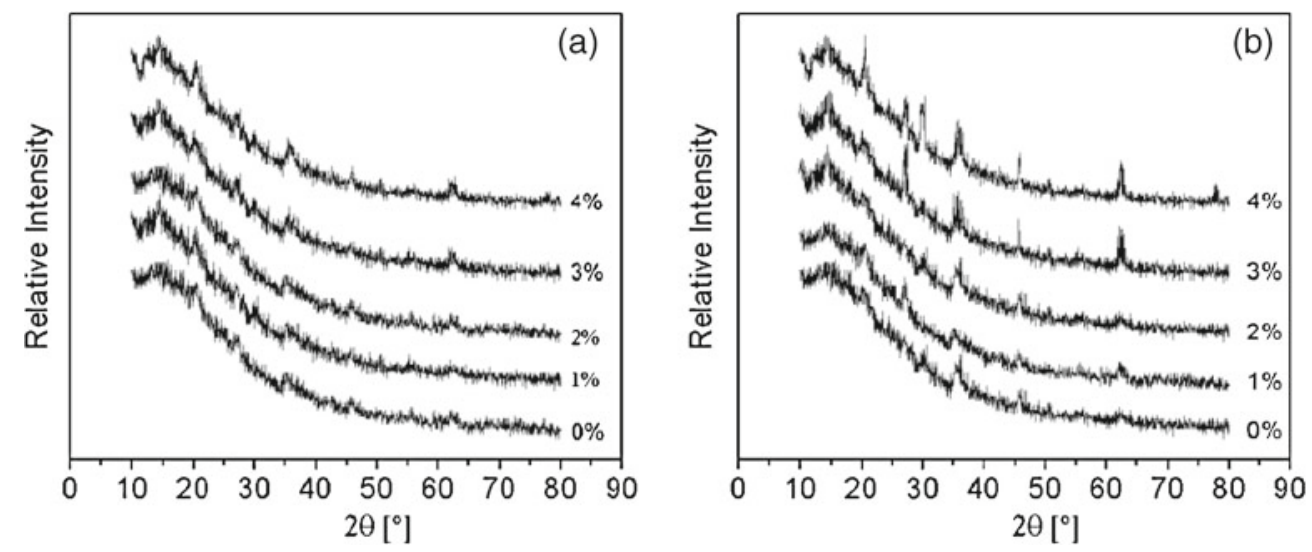

Figure 4. X-ray diffraction intensity profiles for (a) unstretched PVC films and (b) stretched PVCmontmorillonite with varying percentages of montmorillonite.

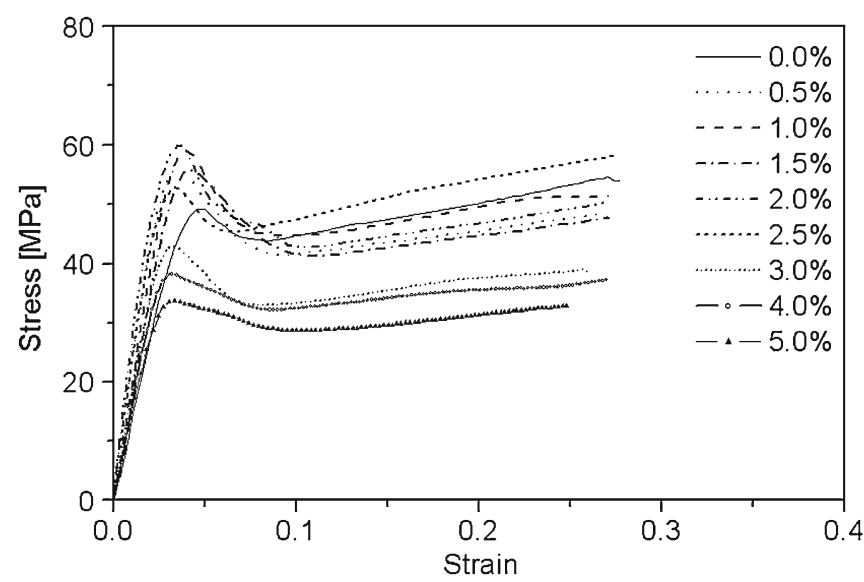

Figure 5. Stress-strain curves of PVC/clay unstretched films containing different amounts of montmorillonite.

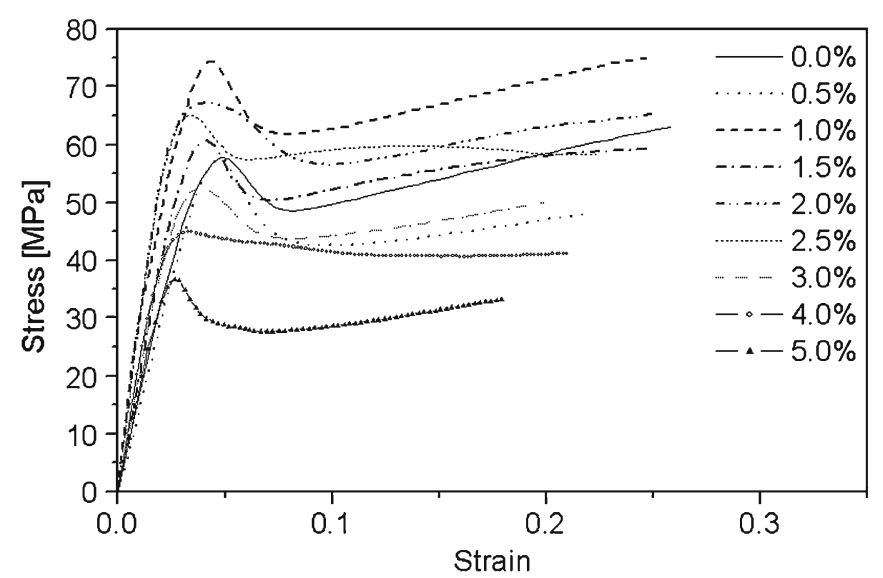

Figure 6. Stress-strain curves of PVC/clay stretched films containing different amounts of montmorillonite. 
Table 2. Comparison of mechanical properties of unstretched (Uns) and stretched (Str) PVC/clay films.

\begin{tabular}{|c|c|c|c|c|c|c|c|c|}
\hline \multirow[b]{2}{*}{ Clay (wt \%) } & \multicolumn{2}{|c|}{ Young's modulus, E (Gpa) } & \multicolumn{2}{|c|}{ Stress at yield, $\sigma^{\mathrm{y}}(\mathrm{MPa})$} & \multicolumn{2}{|c|}{$\begin{array}{l}\text { Strain at yield, } \\
\varepsilon(\% \text { elongation })\end{array}$} & \multicolumn{2}{|c|}{$\begin{array}{l}\text { Strain at break, } \\
\varepsilon(\% \text { elongation })\end{array}$} \\
\hline & Uns & Str & Uns & Str & Uns & Str & Uns & Str \\
\hline $0 \cdot 0$ & $1 \cdot 37$ & $1 \cdot 52$ & $49 \cdot 1$ & $52 \cdot 4$ & $5 \cdot 0$ & $4 \cdot 7$ & $27 \cdot 5$ & $25 \cdot 5$ \\
\hline 0.5 & 1.62 & $1 \cdot 72$ & $55 \cdot 8$ & $61 \cdot 3$ & $4 \cdot 2$ & $4 \cdot 6$ & $26 \cdot 2$ & $23 \cdot 7$ \\
\hline 1.0 & 1.96 & 1.98 & $59 \cdot 2$ & $63 \cdot 2$ & $4 \cdot 0$ & $4 \cdot 4$ & $27 \cdot 3$ & $24 \cdot 6$ \\
\hline $1 \cdot 5$ & $2 \cdot 05$ & $2 \cdot 20$ & $62 \cdot 4$ & $65 \cdot 1$ & $3 \cdot 9$ & $4 \cdot 3$ & $26 \cdot 8$ & $24 \cdot 6$ \\
\hline $2 \cdot 0$ & $2 \cdot 20$ & $2 \cdot 78$ & $59 \cdot 8$ & $68 \cdot 8$ & $3 \cdot 8$ & $4 \cdot 2$ & $26 \cdot 4$ & $24 \cdot 0$ \\
\hline $2 \cdot 5$ & $2 \cdot 32$ & $3 \cdot 28$ & $51 \cdot 8$ & $70 \cdot 5$ & $3 \cdot 8$ & $4 \cdot 0$ & $26 \cdot 0$ & $23 \cdot 8$ \\
\hline $3 \cdot 0$ & $2 \cdot 11$ & $2 \cdot 45$ & $48 \cdot 3$ & $54 \cdot 8$ & $3 \cdot 4$ & 3.8 & $27 \cdot 2$ & $25 \cdot 9$ \\
\hline $4 \cdot 0$ & 1.68 & $2 \cdot 27$ & $40 \cdot 9$ & $46 \cdot 5$ & $3 \cdot 0$ & $3 \cdot 3$ & $26 \cdot 6$ & 24.9 \\
\hline $5 \cdot 0$ & 1.33 & $1 \cdot 70$ & $32 \cdot 9$ & $37 \cdot 0$ & $2 \cdot 4$ & 2.6 & 24.9 & $24 \cdot 6$ \\
\hline
\end{tabular}

The Young's modulus, $E$, expressed in units of GPa, increases initially with increasing clay contents in both unstretched and stretched films, reaches a maximum for films with $2.5 \%$ clay and then decreases on further loading of the clay. The maximum increase in un-stretched case is about $70 \%$ while in the stretched case, it is more than double of that of the pure PVC films. For each composition, the Young's modulus value for stretched film is significantly higher than that for un-stretched film. This can be explained based on the reason that in case of unstretched films, the clay sheets are randomly distributed within the PVC matrix and thus offer more resistance to elongation when compared to the pure PVC films. In case of already stretched films, the structure becomes more stiff because of alignment of polymer segments and clay sheets along the stretch direction and thus offer much higher resistance to further elongation in the same direction. Uniaxial stretching increased the Young's modulus values in these PVC-montmorillonite films.

The 'stress at yield' parameter, $\sigma^{\mathrm{y}}$ measured in units of $\mathrm{MPa}$, follows similar trend. Its maximum increase in case of un-stretched films is about $27 \%$ observed in films with $1.5 \%$ clay contents while in case of stretched films, the maximum increase is $35 \%$ recorded in films with $2.5 \%$ clay contents. Comparing the films of both types with same composition, it is found that stretching has enhanced the value of this parameter also.

The strain at yield point $\varepsilon^{\mathrm{y}}$, expressed as percent elongation, decreases with increasing clay contents in all the films. The values have been reduced almost to half in the films with $5 \%$ clay as compared to the pure PVC films in both cases. Comparing the films of same composition, the value of this parameter is found slightly higher in case of stretched films. This result can also be explained in light of the consequences of stretching in these systems.

The values of stress and strain at break point indicate that it is difficult to trace out any trend against increasing clay contents or effect of stretching variables because the break point values depend heavily on the failure mechanism which is a sample property rather than a material property. However, it is clear when comparing their values in the table, that the uniaxial stretching has left an overall good impact on these parameters.

\section{Conclusions}

PVC-montmorillonite nanocomposites with varying clay contents have been studied for their structural order and tensile properties. Dodecylamine has served as a good compatibilizing agent between the two phases. Films were produced with completely random dispersion of clay layers within the PVC matrix. Degrees of crystallinity and tensile parameters in these films have been determined using X-ray diffraction and stress-strain measurements. Results indicate that the films are predominantly amorphous in nature but increasing clay proportions introduces some degree of order in the structure. Young's modulus and stress at yield point initially increase with increasing clay contents but later start decreasing with further clay loading. The maximum increase in these parameters has been observed in samples with $2.5 \%$ clay contents.

A method has been devised to enhance the degree of crystallinity and values of some tensile parameters in these nanocomposites. This method incorporates uniaxial stretching of films at a temperature slightly lower than the softening temperature of PVC. The results indicate that the structural order has been enhanced and the tensile parameters have been improved upon stretching in this way. Uniaxial stretching up to desired extent has proved to be a successful process in obtaining extra improvement in tensile properties of these PVC-montmorillonite nanocomposite materials.

\section{References}

ASTM D882 - 102003 Standard test method for tensile properties of thin plastic sheeting

Benderly D, Osorio F and Ijdo W L 2008 J. Vinyl Addit. Technol. 14155

Bibi N, Sarwar M, Ishaq M and Ahmad Z 2007 Polym. Polym. Compos. 15313 
Cheremisinoff Nicholas P 1989 Handbook of polymer science and technology: Synthesis and properties (New York: Marcel Dekker, Inc., CRC Press) 1st ed., Vol. 1

Choudhury Tanushree and Misra Nirendra M 2010 Bull. Mater. Sci. 33165

Figueras F et al 1990 Clays Clay Miner. 38257

Gacitua William, Ballerini A and Zhang J 2005 Maderas. Ciencia y tecnologia 7159

Gong Fl, Feng M, C Zhao, Zhang S and Yang M 2004 Polym. Degrad. Stabil. 84289

Hussain Farzana, Hojjati Mehdi, Okamoto Masami and Gorga Russell E 2006 J. Compos. Mater. 401511

Juijn J A, Gisolf J H and Jong W A 1973 Kolloid Z. Z. Polym. 251456
Lepoittevin Benedicte et al 2003 Polymer 442033

McKinney Paul V and Foltz Carl R 1967 J. Appl. Polym. Sci. 11 1189

Pagacz J and Pielichowski K 2009 J. Vinyl Addit. Technol. 1561

Ray S S and Okamoto Masami 2003 Prog. Polym. Sci. 281539

Wan Chaoying, Qiao Xiuying, Zhang Yong and Zhang Yinxi 2003 Polym. Testing 22453

Wang D and Wilkie C A 2002 J. Vinyl Addit. Technol. 8238

Wang Dongyan, Daniel Parlow, Qiang Yao and Wilkie Charles A 2002 J. Vinyl Addit. Technol. 8139

Zulfiqar Sonia, Muhammad Ishaq and Sarwar M I 2008 Surf. Interface Anal. 401195 